\title{
Article \\ Parents and Teachers' Perceptions of the Tone and Emotional
Impact of Education News Coverage
}

Kathryn Shine ${ }^{1, *(1)}$ and Shane L. Rogers 2 (1)

1 School of Media, Creative Arts and Social Inquiry, Curtin University, Bentley 6102, Australia

2 School of Arts and Humanities, Edith Cowan University, Perth 6027, Australia; shane.rogers@ecu.edu.au

* Correspondence: k.shine@curtin.edu.au

Citation: Shine, Kathryn, and Shane

L. Rogers. 2021. Parents and Teachers'

Perceptions of the Tone and

Emotional Impact of Education News Coverage. Journalism and Media 2: 193-207. https://doi.org/10.3390/ journalmedia2020011

Academic Editor:

Andreu Casero-Ripollés

Received: 15 February 2021

Accepted: 19 April 2021

Published: 6 May 2021

Publisher's Note: MDPI stays neutral with regard to jurisdictional claims in published maps and institutional affiliations.

Copyright: (c) 2021 by the authors. Licensee MDPI, Basel, Switzerland. This article is an open access article distributed under the terms and conditions of the Creative Commons Attribution (CC BY) license (https:// creativecommons.org/licenses/by/ $4.0 /)$.

\begin{abstract}
This study examines Australian teachers $(n=268)$ and parents' $(n=206)$ self-reported perceptions of education news coverage and how the coverage affects them. Overall, the participants reported a perception that news coverage of teachers, schools, the education system and standardised testing was generally negative in tone. Participants reported typically feeling demoralised by negative stories and inspired by positive stories. A high importance was placed upon the public perception of education by participants. However, trust in the media reporting of educational issues was low. An exception to this general pattern of findings was that participants did not place as much importance upon the public perception of standardised testing and reported being less affected by negative or positive stories on that topic compared to the other education aspects. This research is one of the few studies to investigate the potential emotional impact that news coverage of education can have on media consumers.
\end{abstract}

Keywords: education news; negative news; positive news; trust in news; impact of news; parents; teachers; schools; solutions journalism

\section{Introduction}

News about K-12 schooling appears regularly in local, metropolitan and national media. Even during the global health crisis caused by the COVID-19 pandemic, education has continued to be a key area of news coverage. Media outlets around the world have reported on school closures and the risk of COVID transmission among schoolchildren (see, for example, Adams 2020; Heffernan 2021; Williams and Hemingway 2020), as they have recognised the relevance and importance of these issues to news consumers. Historically, news coverage of schools has encompassed a diverse range of topics from "hard news" about educational policy and reform through to perennial "soft" picture stories about school fairs and the first day of school. In recent decades, education has grown to become a prevalent and influential area of news coverage (Shine 2019). Although many people have direct contact with schools, they tend to rely on the news media to inform them about the education system more broadly (Mills and Keddie 2010).

Scholars have recognised the impact that news coverage of schooling, schools and teaching can have on public perceptions, and a small but growing body of research into education reporting has emerged. The research has considered the reporting of a broad range of education-related topics from standardised testing to the portrayal of schoolteachers, and the consensus has been that news coverage of education is highly influential. It is said to shape public opinion about schools and teachers and to influence government educational policy (Blackmore and Thorpe 2003; Cohen 2010; Lingard and Rawolle 2004; Mockler 2018; Snyder 2008; Thomson 2004). According to Stack (2006, p. 65), the news media play "a central role in determining the issues that are debated and ultimately how policymakers and the public interpret these issues". This is particularly significant when one considers that related research has pointed to a prevalence of negative reporting of 
education since the 1990s (Baroutsis 2016; Baroutsis and Lingard 2017; Berliner and Biddle 1995; Mockler 2018; Coe and Kuttner 2018; Shine 2017; Wallace 1993).

Most of the research investigating the reporting of education has concentrated on news content. To date, very few studies have explored how news audiences perceive, and respond to, the reporting of educational issues. The limited research that has been undertaken has focused on schoolteachers and suggests that they are concerned about a perceived negative and critical focus of news coverage, and that this type of reporting can upset and affect them (Blackmore and Thorpe 2003; Mackenzie 2007; Shine 2017). The impact of negative coverage is such that some teachers have named it as a factor in their decision to leave the teaching profession (Fetherston and Lummis 2012; Moore 2019). In a recent study of over 2000 Australian teachers, Heffernan et al. (2019) reported that 71\% did not feel that the Australian public appreciates teachers. Our study, outlined here, builds on the limited existing research by outlining the results of a survey of Australian teachers $(n=268)$ and parents $(n=206)$ about their perceptions of, and attitudes towards, news coverage of education. Comparisons between the parent and teacher groups will be identified and explored.

\section{Education in the News}

Traditionally, education received little attention in the news compared to dominant topics such as politics and sport. However, this began to change from the 1980s, when education became a key political issue in developed countries around the world (Shine 2019). As the coverage grew, the nature and tone of the reporting generally became more critical of both school systems and schoolteachers (Simon 1991; Goldstein 2015). While individual teachers may be lauded for their devotion to students, teachers have generally been subject to a range of negative descriptions in news coverage, including "incompetent" (MacMillan 2002, p. 30), "untrustworthy" and "intransigent" (Thomas 2006, p. 218) and "low achievers" (Shine 2015, p. 509). Similarly, while it is not uncommon to hear about a school achieving great results against the odds, the overarching narrative in the news has tended to be that school systems are in crisis and are failing to deliver the desired educational outcomes (Hattam et al. 2009; MacMillan 2002; Wallace 2007).

Print media has tended to be the primary source of education news due, in part, to the often-complex nature of the issues. Hence, much of the research has focused on print and online news reporting of education. However, recent reviews (Coe and Kuttner 2018; Coe et al. 2020) of television news coverage of education suggest that the prevalence of negative reporting of education extends across news platforms. After tracking education stories aired on America's three national broadcast television networks (ABC, CBS and NBC) over 35 years (1980-2015), Coe and Kuttner (2018) found that "violence" and "quality" were the education topics that received the most coverage. "Standards" was the sixth highest topic. Regarding the topics of "quality" and "standards", the authors made the following point:

Notably, an initial qualitative review of the stories in these categories reveals a clear tendency toward negativity. That is, discussions of standards and school quality more often stressed the failures than the successes of education in the United States. What is more, those stories that were positive often focused on specific cases-for instance, a single school or teacher implementing an innovative program. In contrast, the negative stories often presented general trends, such as a set of disappointing test scores across a district, state, or even nationwide. Together, these trends might suggest to an evening news viewer that the school system is generally disappointing, with only minor moments of achievement.

Drawing on framing theory (Entman 1993; Entman 2007; Goffman 1974; Weaver 2007), researchers from various locations, including the US, the UK and Australia, have concluded that education is frequently reported through a "crisis" or "deficit" frame (Baroutsis 2016; MacMillan 2002; O’Neil 2012; Tamir and Davidson 2011; Ulmer 2016). While framing theory has been used across the social sciences and humanities, it is an approach that is favoured 
by communications scholars (Weaver 2007) and, in particular, as a means by which to analyse media texts. According to Tankard (2001, p.96), framing theory recognises the ability of a text or media segment to "define a situation, to define the issues, and to set the terms of the debate". The use of certain frames in a media text calls attention to particular aspects of a subject while omitting others (Entman 1993). In the case of news coverage of a specific topic, for example, the selection of what elements and sources to include, and what leave out, can influence audience reactions to and perceptions of that topic or issue (Entman 1993). In regard to the reporting of education, the coverage has tended to focus on perceived failings of school systems, criticisms of teachers and declining standards (Baroutsis and Lingard 2017; Ulmer 2016; MacMillan 2002). After reviewing the reporting of education in major newspapers, television news programs and online news outlets across the United States, O'Neil (2012) found that the "crisis frame" (p. 6) was dominant in the coverage and that journalists amplified the scope of the crisis by comparing US students' academic performance to that of students from other countries. The coverage focused on problems within education, rarely presenting solutions. This finding highlights the importance of the concept of selection in framing theory. As Entman (1993, p. 52) explains: "To frame is to select some aspects of a perceived reality and make them more salient in a communicating text, in such a way as to promote a particular problem, definition, causal interpretation, moral evaluation, and/or treatment recommendation for the item described." According to $\mathrm{O}^{\prime} \mathrm{Neil}$ (2012), the crisis message that dominated the coverage encouraged public pessimism about the state of the US education system.

The attention given to issues of quality and standards in education news has been noted by numerous researchers (Cohen 2010; Thomas 2006; Thompson and Cook 2014). Coverage of this nature has increased in line with the adoption of standardised testing across many countries around the world. In Australia, such tests include the Program for the International Student Assessment (PISA) and the National Assessment Plan-Literacy and Numeracy (NAPLAN). Studies have shown that the reporting of test results tends to concentrate on areas of decline and unfavourable comparisons rather than improvement (Shine 2015; Stack 2006). While stories about high-performing individual schools or students are covered, most of the reporting focuses on negative aspects of performance (Baroutsis and Lingard 2017).

\section{Public Perceptions and Reactions to News}

Research about public perceptions of education news is limited, but what is available suggests that news consumers have a clear sense of the dominant tone of education reporting. An interview study of 25 Australian teachers' perceptions of news coverage found that $88 \%$ of the teachers interviewed considered education reporting to be predominantly negative (Shine 2017). Furthermore, the coverage was deemed to be unfairly negative and not generally representative of what was happening in schools. More than half of the teachers described news coverage of education as inaccurate and/or unbalanced, and many reported a distrust of the news media and journalists. Such views are not uncommon, according to the findings of larger studies. For example, the Reuters Institute Digital News Report 2019 surveyed 75,000 news consumers from 38 countries and found that almost 4 out of 10 participants considered the news to be too negative. The level of trust in news had decreased to $42 \%$, and only about half of the respondents ( $49 \%$ ) trusted the media they themselves use. Additionally, news avoidance had increased, with the most common reason to avoid news being that it had a negative impact on mood (Newman et al. 2019).

Research has also indicated that the tone of news can produce emotional responses in news consumers (de Hoog and Verboon 2020; Baden et al. 2019; Johnston and Davey 1997; Marin et al. 2012; McIntyre and Gibson 2016; McIntyre and Gyldensted 2018; McNaughtonCassill 2001; Newman et al. 2019; Szabo and Hopkinson 2007). For example, in a recent psychological study of the effect of general news on emotions, de Hoog and Verboon (2020) had 63 American adults report their mood and news exposure five times per day for 10 days. They reported a small but statistically significant effect of negative news coverage 
on daily mood. Other researchers have also found a positive impact of positive news, such as McIntyre and Gibson (2016), who experimentally manipulated the tone of news stories to demonstrate how positive news can lift the mood of the reader. While research has investigated the emotional impact of news in a broad sense, there is a lack of research specifically investigating the potential impact of education news on relevant stakeholders (such as teachers and parents).

\section{The Present Study}

In her interview study of Australian teachers, Shine (2017) found that almost all participants considered media reporting of education to be predominately negative. The present study extends upon that qualitative work by conducting a quantitative examination (via survey) of a larger sample size of teacher and parent views regarding the perceived general positive/negative tone of education news media. The inclusion of parents meant that we could ascertain whether teachers were particularly sensitive to news reports about education or whether their perceptions were shared by another section of the community, albeit one that also has a connection to schooling. We hypothesised that, like in Shine (2017), most participants would perceive education news to contain a generally negative tone. Additionally, we surveyed participants' perceptions of different aspects of education-the reporting of news about teachers, schools, the Australian education system and NAPLAN testing. We surveyed views about Australia's National Assessment Plan-Literacy and Numeracy (NAPLAN), as NAPLAN testing has been controversial since its inception about 10 years ago (Mockler 2015; Rogers et al. 2016, 2018; Rose et al. 2018; Thompson and Cook 2014) and, as previously discussed, NAPLAN is regularly in the news (Mockler 2013, 2015; Shine 2015; Thompson and Lasic 2011).

There is an established literature demonstrating that news media can impact mood in negative (de Hoog and Verboon 2020; Baden et al. 2019; Johnston and Davey 1997; Marin et al. 2012; McNaughton-Cassill 2001; Newman et al. 2019; Szabo and Hopkinson 2007) and positive ways (Baden et al. 2019; McIntyre and Gibson 2016). Therefore, we hypothesised that teachers and parents might report experiencing a negative reaction and positive reaction to negative and positive education news, respectively. It has also been suggested that a contributing factor to the psychological impact of news is a person's perceptions regarding how important or relevant the news is to them (de Hoog and Verboon 2020). Therefore, to help explain why we might find that some participants report a strong reaction to education news, we also explored the extent to which the surveyed participants felt that the public perception of education was important. We hypothesised that since both teachers and parents have a personal investment in education, most would care about the public perception of education. This is also why, in the present study, we investigated perceptions across different aspects of education that differ in the extent of personal relevance (i.e., teachers, schools, the education system and NAPLAN). We were anticipating that teachers would be more impacted by news media that have a higher level of personal relevance to them (teachers and schools) compared to more system-level aspects of education (the education system and NAPLAN). We also asked our participants the extent to which they have trust in news coverage. As per the recent Reuters report (Newman et al. 2019), we hypothesised that trust in news reporting about education would be relatively low. 


\section{Method}

\subsection{Participants}

Participants were recruited by posting an advertisement about the study on the Facebook research page of one of the authors (S.R.). The sample consisted of 268 teachers $(M$ age $=42.54, S D$ age $=8.92 ; 87 \%$ female $)$ and 206 parents $(M$ age $=42.79, S D$ age $=6.48 ;$ $91 \%$ female). Included within the teacher sample were 11 school principals. For the parent sample, all participants indicated that they had school-aged children (primary or secondary) at the time of the survey. At the time of responding, the participants lived across the states and territories of Australia, with most of the teacher sample coming from Queensland (30\%) and most of the parent sample coming from Western Australia (46\%); see Table 1.

Table 1. Frequency statistics for the Australian state/territory of residence of participants.

\begin{tabular}{ccc}
\hline & Teachers & Parents \\
\hline Australian Capital Territory & $1(0.4 \%)$ & $0(0 \%)$ \\
New South Wales & $57(21 \%)$ & $28(14 \%)$ \\
Northern Territory & $1(0.4 \%)$ & $0(0 \%)$ \\
Queensland & $80(30 \%)$ & $39(19 \%)$ \\
South Australia & $21(8 \%)$ & $9(4 \%)$ \\
Tasmania & $7(3 \%)$ & $4(2 \%)$ \\
Victoria & $51(19 \%)$ & $31(15 \%)$ \\
Western Australia & $45(17 \%)$ & $95(46 \%)$ \\
\hline
\end{tabular}

Note: Five participants ( $2 \%$ ) of the teacher sample did not respond to this question.

\subsection{Measures}

In this study, we used an online questionnaire to assess participant perceptions about news media reporting of several aspects of education: teachers, schools, the education system and NAPLAN. Below, we describe the questions by sub-section.

Participant exposure to education news. To assess participant self-reported exposure to news with an education focus, we asked several questions. First, participants were asked, "How often do you read (or listen to) news stories?" on the following response scale: (1) Multiple times per day; (2) About once a day; (3) A few times per week; (4) About once a week; (5) A few times per month; (6) About once a month; (7) A few times per year; (8) About once a year; (9) Less than once a year. Participants were then asked, "Approximately what proportion of the news articles you encounter are focused on education?" on the following response scale: (1) $1 \%$ or less; (2) $2 \%$; (3) $5 \%$; (4) $10 \%$; (5) $15 \%$; (6) $20 \%$; (7) $25 \%$; (8) $30 \%$ or greater.

Perceptions of positive/negative tone of education media coverage. Participants' general perception of the overall positive or negative tone of education media was assessed via the question "In general, I feel like the media coverage of is typically:" on the following response scale: (1) Very negative; (2) Somewhat negative; (3) Neutral; (4) Somewhat positive; (5) Very positive. This item was repeated, where the blank space was replaced with teachers, schools, the education system or NAPLAN. 
Reactions to positive and negative education media coverage. To assess participants' negative reactions to negative media, participants were asked the question "When I hear/read a NEGATIVE media story about I find it to be DEMORALISING", and to assess positive reactions to positive media, the question used was "When I hear/read a POSITIVE media story about , I find it to be INSPIRING". For both questions, the following response scale was used: (1) Not at all; (2) A little bit; (3) Quite a bit; (4) A lot. Both questions were repeated for teachers, schools, the education system and NAPLAN. The terms "demoralising" and "inspiring" were chosen based on specific suggestions in the literature that educators can find negative education news items demoralising (Mackenzie 2007) and positive items inspiring (Liu and Tsao 2013).

Trust in the media coverage of education. The general level of trust in education media was assessed via the question "When I hear/read a media story about I feel like I can trust what I am hearing/reading" on the following response scale: (1) Not at all; (2) A little bit; (3) Quite a bit; (4) A lot. This item was repeated for teachers, schools, the education system and NAPLAN.

The perceived importance of the public perception of education. To assess how important the participants feel the public's perception of education is, we asked the question "How

is/are perceived by the public is important to me". The following response scale was used: (1) Not at all; (2) A little bit; (3) Quite a bit; (4) A lot. This item repeated for teachers, schools, the education system and NAPLAN.

\section{Results}

\subsection{Participant Exposure to Education News}

A few preliminary items were included in our survey to better understand the extent of education news exposure within our samples. Participants generally reported a high exposure to news, with teachers reporting slightly more frequent news consumption $\left(t(472)=2.34, p=0.02, r^{2}=0.01\right)$. The majority of participants reported hearing/reading news at least once per day (approx. 84\%), and commonly, participants reported hearing/reading news multiple times per day (approx. 57\%); see Figure 1a. News with an education focus appears to be a frequent part of participant experience with news, as $67 \%$ of teachers and $44 \%$ of parents estimated that education-focused news comprises at least $10 \%$ of the news items they consume; see Figure $1 \mathrm{~b}$. This difference between teacher and parent samples reached statistical significance $\left(t(472)=3.97, p<0.001, r^{2}=0.03\right)$.
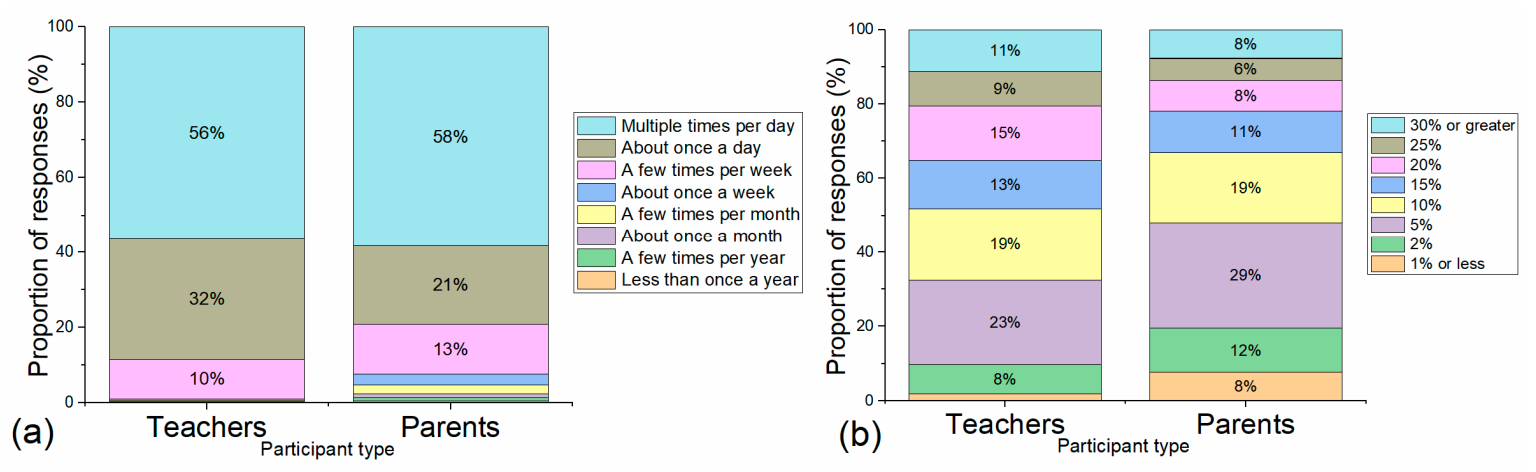

Figure 1. Teacher and parent self-reported responses to questions that assessed (a) the frequency with which they listen/read to news and (b) their estimated proportion of the news they consume that has an education focus. 


\subsection{Perceptions of Positive/Negative Tone of Education Media Coverage}

Participants reported their perception of the general tone of education media coverage as largely negative; see Figure $2 \mathrm{a}, \mathrm{b}$. For teachers, a significant difference was found among different aspects of education, $F(3,801)=50.74, p<0.001, \eta_{p}{ }^{2}=0.16$. Statistically, the pattern from most negative to least negative is as follows: Teachers $=$ education system $(t(267)=0.48, p=0.63)>\operatorname{schools}\left(t(267)=4.73, p<0.001, r^{2}=0.08\right)>\operatorname{NAPLAN}(t(267)=6.01$, $p<0.001, r^{2}=0.12$; see Figure 1a. Teachers perceive the media coverage of teachers, schools and the education system as largely negative (approx. 85\%). Many teachers also perceive NAPLAN as receiving generally negative media coverage (55\%), but this is substantially lower compared to the other rated aspects of education. Our process of making follow-up comparisons was to rank, in order, the means and then conduct three planned comparisons in a stepwise fashion to determine any statistically significant differences. Therefore, we applied a Bonferroni correction, adjusting our accepted p-value criterion to be 0.017 (i.e., $0.05 / 3=0.017)$.

For parents, a significant difference was found among different aspects of education, $F(1,205)=26.76, p<0.001, \eta_{p}{ }^{2}=0.12$. The pattern is education system $=$ NAPLAN $(t(205)=0.50, p=0.62)>$ schools $\left(t(205)=3.62, p<0.001, r^{2}=0.06\right)=$ teachers $(t(205)=2.23$, $\left.p=0.02, r^{2}=0.02\right)$; see Figure $2 b$. Compared to the parents, the teachers typically reported perceiving more negative news coverage on teachers $\left(t(472)=11.01, p<0.001, r^{2}=0.20\right)$, schools $\left(t(472)=7.02, p<0.001, r^{2}=0.09\right)$ and the education system $(t(472)=4.85, p<0.001$, $\left.r^{2}=0.05\right)$, whereas for NAPLAN, parents reported perceiving more negative news coverage $\left(t(472)=2.60, p=0.01, r^{2}=0.01\right)$. However, it must still be noted that despite parents generally perceiving less negative media coverage than that perceived by teachers, the perception of negative media coverage was, overall, high for parents across all aspects of education (approx. 64\%). In sum, both teachers and parents mostly perceive media coverage of education as negative, with this being more pronounced among teachers.

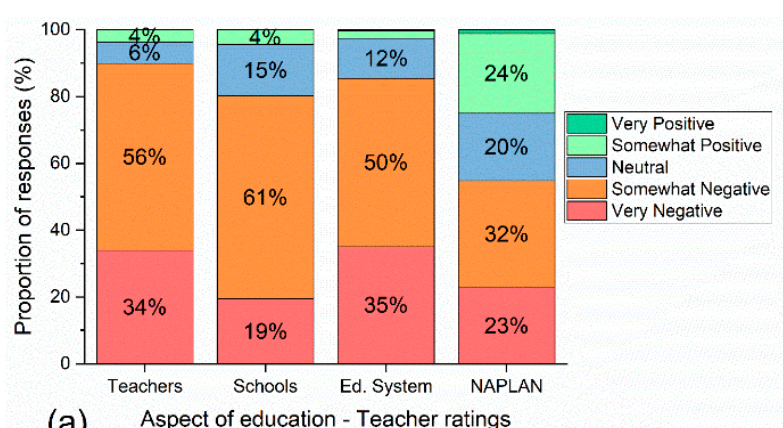

(a) Aspect of education - Teacher ratings

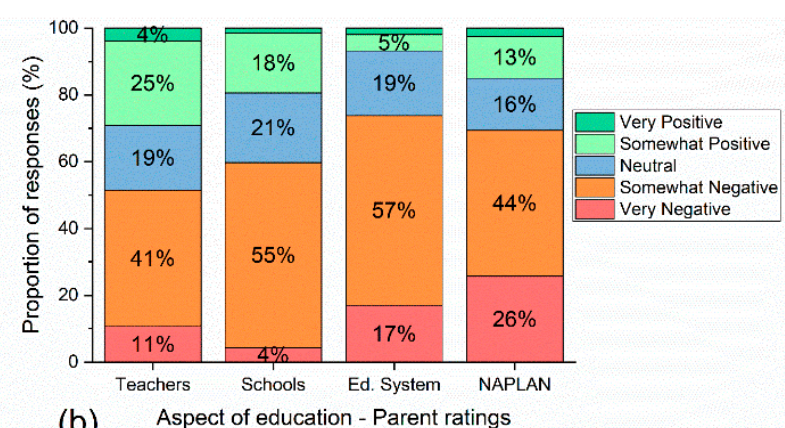

(b)

Figure 2. The perception of the positive/negative tone of media reports across different aspects of education for (a) teachers, and (b) parents. Please note that the labels for percentages lower than $3 \%$ are omitted from the charts. 


\subsection{Trust in the Media Coverage of Education}

Both teachers and parents predominately reported low trust in the news media coverage of education, with around $97 \%$ of teachers and $87 \%$ of parents reporting trusting media coverage "a little bit" or "not at all" across all aspects of education; see Figure 3a,b. Compared to parents, teachers reported lower trust in media reporting of all aspects of education (pattern of mean differences: teachers, $t(472)=7.96, p<0.001, r^{2}=0.12$; schools, $t(472)=5.43, p<0.001, r^{2}=0.06$; education system, $t(472)=4.21, p<0.001, r^{2}=0.04$; NAPLAN, $\left.t(472)=2.33, p<0.001, r^{2}=0.01\right)$. Across the different aspects, teachers reported the lowest trust in the media reporting about teachers compared with other aspects of education (pattern of mean differences, $F(3,801)=10.81, p<0.001, \eta_{p}{ }^{2}=0.04$ : NAPLAN $=$ education system $(t(267)=0.13, p=0.90)=\operatorname{schools}(t(267)=0.001, p=0.99)>$ teachers $\left.\left(t(267)=5.43, p<0.001, r^{2}=0.06\right)\right)$, whereas parents reported the lowest trust in NAPLAN media coverage (pattern of mean differences, $F(3,615)=9.04, p<0.001, \eta_{p}{ }^{2}=0.04$ : teachers $=$ schools $(t(205)=0.92, p=0.41)=$ education system $(t(205)=1.83, p=0.07)>$ $\operatorname{NAPLAN}\left(t(205)=2.56, p=0.01, r^{2}=0.03\right)$. In sum, both teachers and parents generally have little trust in the media coverage of education across all aspects, with teachers being slightly more distrustful compared to parents.

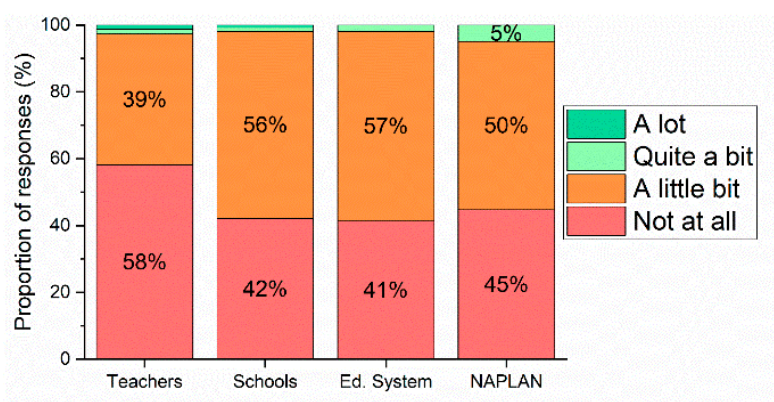

(a)

Aspect of education - Teacher ratings

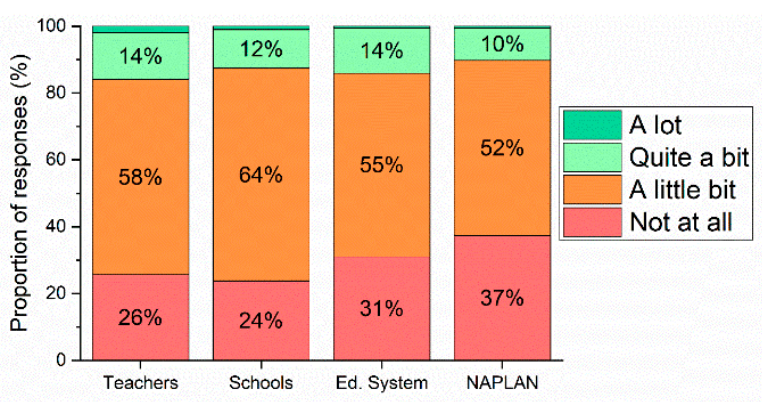

(b)

Figure 3. The extent of trust in media reporting of different aspects of education for (a) teachers and (b) parents. Please note that the labels for percentages lower than $3 \%$ are omitted from the charts.

\subsection{Reactions to Positive and Negative News Media Coverage}

The results suggest that negative media stories have the potential to have a negative impact on most teachers and parents; see Figure $4 \mathrm{a}, \mathrm{b}$. Around $81 \%$ of teachers reported that a negative news story about teachers, schools or the education system demoralises them "quite a bit" or "a lot". This was not the case for NAPLAN, where only $26 \%$ of teachers reported that a negative NAPLAN story would demoralise them to such an extent. For teachers, the pattern among different aspects regarding being demoralised over negative coverage is as follows: $F(3,801)=266.37, p<0.001, \eta_{p}^{2}=0.50$, teachers $>$ schools $\left(t(267)=6.86, p<0.001, r^{2}=0.15\right)>$ education System $(t(267)=4.58, p<0.001$, $\left.r^{2}=0.07\right)>$ NAPLAN $\left(t(267)=16.38, p<0.001, r^{2}=0.50\right)$. Compared with teachers, the parents reported a significantly lesser extent of demoralisation from negative news stories for all aspects of education media coverage (i.e., teachers, $t(472)=11.74, p<0.001, r^{2}=0.23$; schools, $t(472)=9.25, p<0.001, r^{2}=0.15$; education system, $t(472)=6.63, p<0.001, r^{2}=0.09$ ), except for NAPLAN with no significant difference $(t(472)=0.001, p=0.99)$. However, a substantial number of parents (around 50\%) did report being demoralised "quite a bit" to "a lot" by negative news stories about teachers, schools and the education system; see Figure $4 \mathrm{~b}$. Like the teachers, the parents were typically not as demoralised by negative news stories about NAPLAN compared to the other aspects of education. The pattern of means for parents regarding the extent of demoralisation from negative education news is $F(3,615)=34.10, p<0.001, \eta_{p}{ }^{2}=0.14$, teachers $=$ schools $(t(205)=0.58, p=0.57)=$ education system $\left(t(205=0.47, p=0.63)>\right.$ NAPLAN $\left(t(205)=7.25, p<0.001, r^{2}=0.20\right)$. In sum, a substantial proportion of teachers and parents report feeling demoralised "quite a bit" or 
"a lot" in response to negative news items about teachers, schools and the education system. This is especially true for the teachers. Neither teachers nor parents appear to be as affected by negative news stories about NAPLAN.
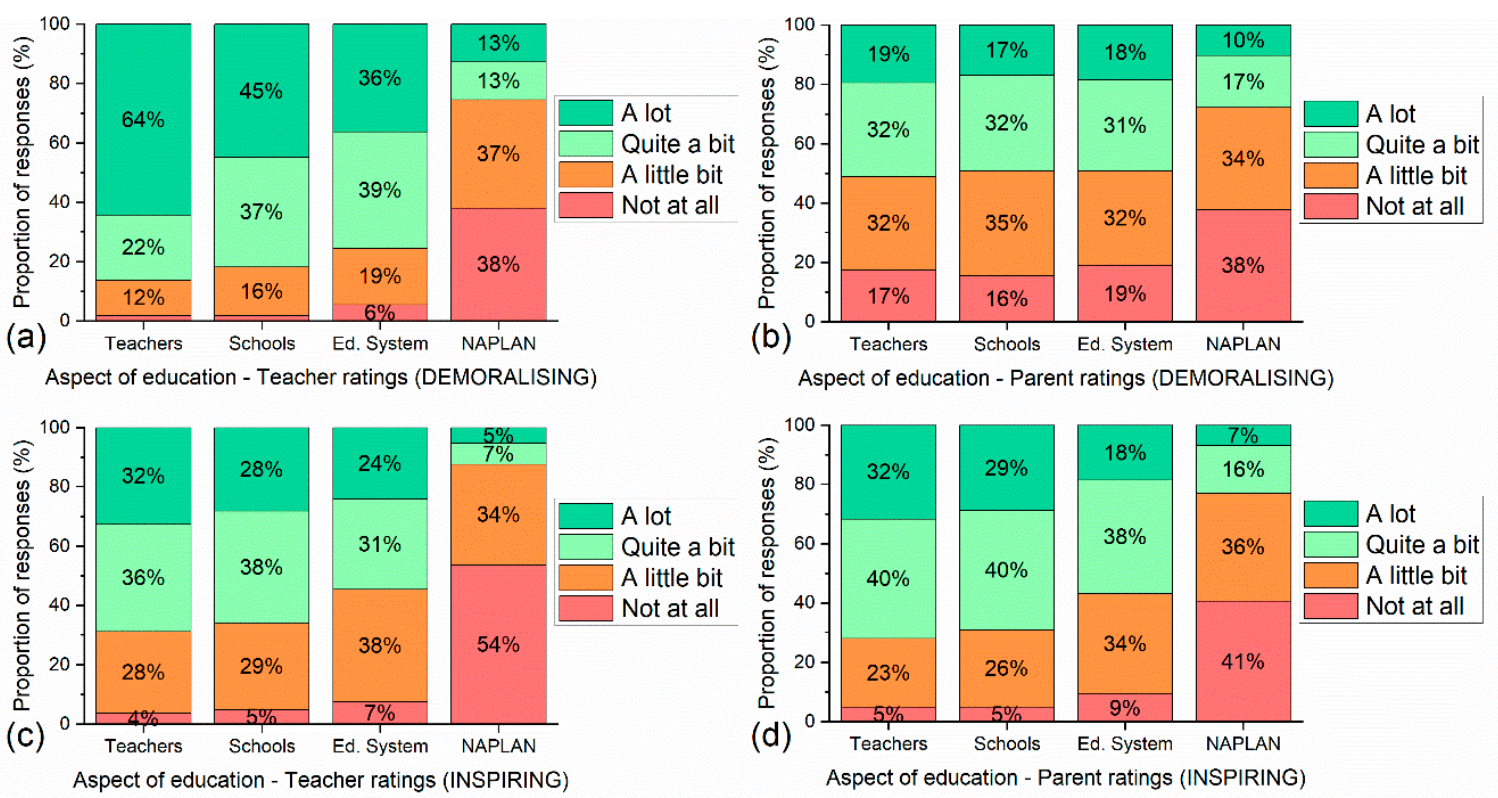

Figure 4. The extent of demoralisation felt upon hearing/reading negative news stories about education for (a) teachers and (b) parents. Additionally, the extent of inspiration felt upon hearing/reading positive news stories about education for (c) teachers and (d) parents.

While the results suggest that negative news can be demoralising, it was also found that positive news can be inspiring. Around $64 \%$ of both teachers and parents reported that when they hear/read about a positive news story about teachers, schools or the education system, they feel inspired "quite a bit" or "a lot"; see Figure 4c,d. There is no significant difference between teachers and parents for these aspects (all $p>0.05$ ), but teachers reported being slightly less inspired than parents regarding positive news stories about NAPLAN $\left(t(472)=3.12, p=0.002, r^{2}=0.20\right)$. However, this difference is small, and both teachers and parents report minimal feelings of inspiration from positive NAPLAN news. Indeed, $54 \%$ of teachers and $41 \%$ of parents responded "not at all" to this question. The pattern of differences across the different aspects was similar for teachers and parents for the questions about inspiration with the following pattern for teachers: $F(3,801)=342.94$, $p<0.001, \eta_{p}{ }^{2}=0.56$, teachers $>$ schools $\left(t(267)=3.10, p=0.002, r^{2}=0.03\right)>$ education system $\left(t(267)=5.93, p<0.001, r^{2}=0.12\right)>\operatorname{NAPLAN}\left(t(267)=18.43, p<0.001, r^{2}=0.56\right)$; and for parents: $F(3,615)=151.12, p<0.001, \eta_{p}{ }^{2}=0.42$, teachers $=$ schools $(t(205)=2.07$, $\left.p=0.04, r^{2}=0.02\right)>$ education system $\left(t(205)=6.37, p<0.001, r^{2}=0.17\right)>$ NAPLAN $\left(t(205)=11.95, p<0.001, r^{2}=0.41\right)$. In sum, the level of inspiration from positive education news stories was found to be similar between teachers and parents, where members of both groups mostly felt inspired "quite a bit" or "a lot" by positive news about teachers, schools and the education system. Positive news stories about NAPLAN were not associated with much inspiration for either teachers or parents. 


\subsection{The Perceived Importance of the Public Perception of Education}

Overall, the perceived importance placed upon the public perception of education is high among both teachers and parents, except for NAPLAN, which is low; see Figure $5 \mathrm{a}, \mathrm{b}$. The pattern of differences across aspects for teachers is as follows: $F(3$, $801)=456.65, p<0.001, \eta_{p}{ }^{2}=0.63$, teachers $>$ schools $\left(t(267)=4.57, p<0.001, r^{2}=0.07\right)>$ education system $\left(t(267)=4.17, p<0.001, r^{2}=0.06\right)>$ NAPLAN $(t(267)=21.38, p<0.001$, $r^{2}=0.63$ ). Almost all teachers (around $90 \%$ ) responded "quite a bit" or "a lot" of perceived importance of the public perception of education for teachers, schools and the education system. A stand-out was the teachers' perception of the importance of the public perception of teachers, where $85 \%$ stated "a lot". Compared with parents, the teachers generally reported greater importance of the public perception of teachers $(t(472)=9.70, p<0.001$, $\left.r^{2}=0.17\right)$, schools $\left(t(472)=8.15, p<0.001, r^{2}=0.12\right)$ and the education system $(t(472)=5.74$, $\left.p<0.001, r^{2}=0.07\right)$. However, parents did still report a generally strong perceived importance of these education aspects (around 71\% responded "quite a bit" or "a lot"), although just slightly less than teachers did. The pattern of differences across aspects for parents was as follows: $F(3,615)=118.85, p<0.001, \eta_{p}{ }^{2}=0.37$, teachers $=$ schools $(t(205)=1.12$, $p=0.27)=$ education system $(t(205)=0.76, p=0.45)>\operatorname{NAPLAN}(t(205)=12.87, p<0.001$, $\left.r^{2}=0.45\right)$. There was no significant difference regarding the perception of NAPLAN between teachers and parents $(t(472)=0.76, p=0.45)$, and for both groups, the perceived importance of the public perception of NAPLAN was low, with around 75\% reporting "not at all" or "a little bit". In sum, teachers and parents generally reported feeling that the public perception of teachers, schools and the education system was quite important to them. They did not typically feel the same way about NAPLAN.
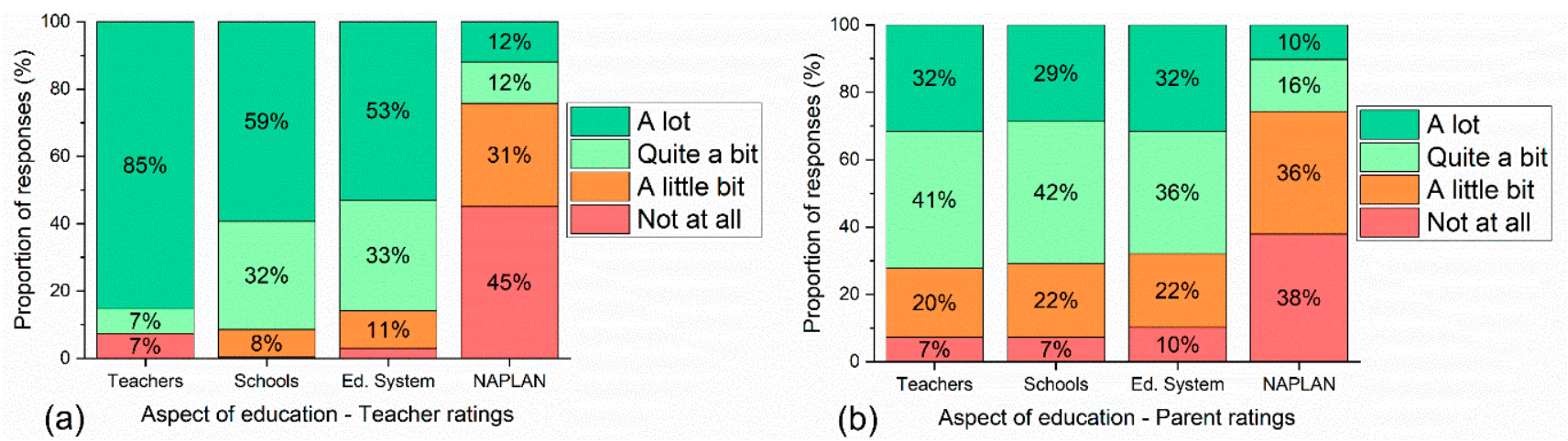

Figure 5. The perceived importance of public perception of different aspects of education for (a) teachers and (b) parents.

\section{Discussion}

It is worth noting from the outset that the group of people surveyed for this study were regular consumers of news. More than $80 \%$ engaged with the news at least once a day and more than $50 \%$ reported hearing or reading news multiple times a day. The most common estimate by participants regarding the proportion of news consumed that had an education focus was about $5-10 \%$. Therefore, the participant perceptions of education news in our study were based on frequent engagement with news, and education news in particular, which, we argue, adds weight to the findings reported here. As per Shine's (2017) previous study, this research found that Australian teachers typically perceive news to be predominately negative. Our extension of Shine's (2017) work was conducted to show that these results extend to a large sample of teachers, and also parents. It could be argued that teachers have a particular sensitivity to news coverage of them and their work environment, which may skew their perception. The same argument cannot be applied to parents, so we argue that this broader view about the negativity of education reporting is significant. 
For both teachers and parents, news coverage relating to the education system was considered an area that received generally negative coverage (85\% of teachers and $62 \%$ of parents). These findings support Tankard's (2001, p. 96) argument that media framing can have "subtle but powerful effects on the audience", who are often not even aware that the selection and emphasis of certain elements in the reporting may be influencing their perspectives and opinions. A high proportion of parents (70\%) also perceived the reporting of NAPLAN to be generally negative. As previously discussed, standardised tests such as PISA and NAPLAN receive a high degree of media attention relative to other educational issues (Shine 2015). Other research has also pointed to the predominantly critical tone of the reporting of standardised testing in education (Dixon et al. 2013; Shine 2015), including a study of Australian news coverage of PISA from 2001 to 2014 (Baroutsis and Lingard 2017) that identified three dominant frames in the reporting: counts and comparisons, criticisms and contextual issues. The result of this framing was that Australia's educational systems and its teachers were generally depicted as inferior to those of other countries and in need of improvement. Certain important elements were absent from the coverage, including the fact that the number of countries participating in PISA had increased significantly over time, thus affecting the ranks of the countries that took part. Furthermore, while certain Australian states had performed well at various times, the reporting was "fixated on national average scores and international comparisons" (Baroutsis and Lingard 2017, p. 446). This again highlights the impact of selection in news framing. Standardised tests are only one measure of large and highly complex educational systems. This and other research suggest the news media's preoccupation with testing, standards and performance (Baroutsis and Lingard 2017; Thompson and Cook 2014) may be creating an overly and unfairly negative tone in the reporting, as perceived by teachers and parents.

Something that surprised us was the strength of responses from many participants. Pertaining to perceptions of the media reporting of teachers, schools and the education system, most participants felt it to be generally negative $(85 \%$ of teachers and $62 \%$ of parents), had little trust in the reporting (98\% of teachers and $86 \%$ of parents), felt strongly demoralised by negative education news ( $81 \%$ of teachers and $50 \%$ of parents) and strongly inspired by positive education news (63\% of teachers and $66 \%$ of parents) and reported that the public perception of education was quite important to them $(90 \%$ of teachers and $71 \%$ of parents). We argue that the strength of responses highlighted by the present study suggests that news coverage might have a larger emotional impact on news consumers than what might be intuitively expected.

The participants were generally invested in the issue of news coverage of education. Most teachers and parents cared about how education systems, teachers and schools were portrayed to the public. This finding makes a significant contribution to the literature about news coverage of education, and news more generally, as members of the public have rarely been asked about the importance that they place on the way in which various issues are represented in the news. In this case, the finding is arguably not surprising for teachers, as it is their chosen profession and, for most, would likely form a large part of their identity. However, a similarly strong reaction from parents was not expected. We argue that this high level of personal importance placed upon education can contribute towards explaining the other finding that teachers and parents generally report being emotionally affected by news coverage of education.

In terms of the impact of the reporting, a high proportion of teachers (86\%) reported being very (i.e., "quite a bit" or "a lot") demoralised by negative news stories about teachers. The majority of the teachers interviewed said that negative stories about schools and the education system were also demoralising. In the present study, we did not go on to ask if the negative media reporting demoralises teachers to the extent that it reduces job satisfaction, so we cannot provide any definitive conclusions about that. However, it is reasonable to hypothesise that this might be the case, especially as previous research (Mackenzie 2007; Fetherston and Lummis 2012) and surveys (Moore 2019) have found that critical media coverage can be a source of teacher dissatisfaction and has been cited as a 
reason why teachers leave the profession. We argue that this is something that warrants further research attention.

The discouraging effect of negative coverage was also seen to a large extent among the parent participants. About half of the parents found negative coverage relating to teachers/schools/the education system to be demoralising. This finding reinforces the conclusions of previous research reporting that exposure to negative general news can influence mood and even affect mental health (de Hoog and Verboon 2020; Baden et al. 2019; Johnston and Davey 1997; Marin et al. 2012; McNaughton-Cassill 2001; Newman et al. 2019; Szabo and Hopkinson 2007). On the other hand, we also found that the majority of both teachers and parents typically find positive news stories about teachers, schools and the education system to be inspiring (i.e., approximately 65\% reported "quite a bit" or "a lot"). This is consistent with other studies reporting how positive news can have a positive emotional impact on news consumers (Baden et al. 2019; McIntyre and Gibson 2016).

As mentioned above, the participant responses across the different education aspects of teachers, schools and the education system were overall quite similar. There was, however, a large contrast between these aspects and NAPLAN. Participants did not place much importance on how the public perceives NAPLAN (around 75\% of teachers and parents responded "not at all" or "a little bit"). The annual tests and the release of the tests still make headlines every year in Australia but our research suggests that news consumers are not particularly interested in, or invested in, such coverage. Nor do they believe it, with $95 \%$ of teachers and $89 \%$ of parents saying they trusted news reports of NAPLAN only a little bit or not at all.

Overall, there was little trust in news reporting for both teachers and parents, consistent with other work that points to a current lack of faith in news media in general (Newman et al. 2019). Almost all of the teachers (97\%) reported having no trust or only a little bit of trust in news coverage of education. Significantly, parents also reported low levels of trust. Studies such as this confirm that distrust is a genuine and widespread issue for mainstream news outlets, as other surveys and polling have been suggesting.

We argue that journalists and editors need to be made aware of research such as this and acknowledge the real impact of their reporting. According to Fink (2019, p. 40), journalists "often do not recognize the power they wield over members of the public, and thus fail to treat them with sufficient care and respect." This points to a disconnect between journalists and their audiences. Better engaging with the public is one step in improving this connection. Another strategy is to actively seek out more positive news stories. One way to do is to adopt a "solutions-focused" approach to reporting. Advocates of solutions journalism argue this does not mean reporting "soft" good news stories, but rather that it is about giving coverage to initiatives that have been shown to address social problems (McIntyre and Lough 2019; Thier 2016). Scholars who have examined the reporting of education (O'Neil 2012; Shine 2017) have recommended that a solutions approach be adopted to counter the dominant negative tone. According to O'Neil (2012, p. 7), in order to overcome the crisis frame, critical news reports of education "should always be accompanied by concrete solutions that address problems".

\section{Conclusions}

In this study, we examined public perceptions of news coverage of education and the emotional effect of this coverage. Our survey participants were teachers $(n=268)$ and parents $(n=206)$ from across Australia and were almost entirely female. Our findings are, therefore, limited to the Australian (and female) context, and future research is required to determine if similar findings exist in other locations and across genders. In our study, high proportions of both teachers and parents considered news coverage of education to be negative in tone. Relatively high numbers in both groups also reported being demoralised by negative coverage about teachers, schools and the education system. Additionally, the participants typically reported being inspired by positive stories. Although they did not always trust news coverage, they cared about how education was presented to the 
public. Teachers may be more sensitive to news coverage that relates to their work and their work environment, but this study found that parents had similar views to teachers about the nature of the coverage. This is significant, we argue, because news organisations are targeting the high number of parents in the community when they cover education news. Education has become a prominent topic of news coverage because editors and journalists have recognised how important educational issues are to parents. Yet, this research suggests that parents are dissatisfied with the overly negative tone of the coverage and would welcome a better balance in education news.

Author Contributions: Conceptualisation, K.S. and S.L.R.; Data curation, S.L.R.; Formal analysis, S.L.R.; Methodology, S.L.R.; Writing—original draft, K.S. and S.L.R.; Writing—review and editing, K.S. All authors have read and agreed to the published version of the manuscript.

Funding: This research received no external funding.

Institutional Review Board Statement: The study was conducted according to the guidelines of the Declaration of Helsinki, and approved by the Ethics Committee of Edith Cowan University (ethics reference number = 2019-00031-ROGERS; date of approval = 26 February 2019).

Informed Consent Statement: Informed consent was obtained from all subjects involved in the study.

Data Availability Statement: The data presented in the study are openly available in FigShare at https:/ / doi.org/10.6084/m9.figshare.14472819.v1 (accessed on 28 April 2021).

Conflicts of Interest: The authors declare no conflict of interest.

\section{References}

Adams, Richard. 2020. Children Need Back-to-School Plan Urgently, Doctors Tell Johnson. The Guardian. June 17. Available online: https:/ / www.theguardian.com/education/2020/jun/17/children-need-back-to-school-plan-urgently-doctors-tell-borisjohnson (accessed on 1 February 2021).

Baden, Denise, Karen McIntyre, and Fabian Homberg. 2019. The impact of constructive news on affective and behavioural responses. Journalism Studies 20: 1940-59. [CrossRef]

Baroutsis, Apsa. 2016. Media accounts of school performance: Reinforcing dominant practices of accountability. Journal of Education Policy 31: 567-82. [CrossRef]

Baroutsis, Apsa, and Bob Lingard. 2017. Counting and comparing school performance: An analysis of media coverage of PISA in Australia, 2000-2014. Journal of Education Policy 32: 432-49. [CrossRef]

Berliner, David C., and Bruce J. Biddle. 1995. The Manufactured Crisis: Myths, Fraud, and the Attack on America's Public Schools. Reading: Addison-Wesley.

Blackmore, Jill, and Stephen Thorpe. 2003. Media/ting change: The print media's role in mediating education policy in a period of radical reform in Victoria, Australia. Journal of Education Policy 18: 577-95. [CrossRef]

Coe, Kevin, and Paul J. Kuttner. 2018. Education coverage in TV News: A typology and analysis of 35 years of topics. AERA Open 4: 1-13. [CrossRef]

Coe, Kevin, Paul J. Kuttner, Manusheela Pokharel, Dakota Park-Ozee, and Meaghan McKasy. 2020. The "discourse of derision" in news coverage of education: A mixed methods analysis of an emerging frame. American Journal of Education 126: 423-45. [CrossRef]

Cohen, Jennifer L. 2010. Teachers in the news: A critical analysis of one US newspaper's discourse on education 2006-2007. Discourse: Studies in the Cultural Politics of Education 31: 105-19. [CrossRef]

de Hoog, Natascha, and Peter Verboon. 2020. Is the news making us unhappy? The influence of daily news exposure on emotional states. British Journal of Psychology 111: 157-73. [CrossRef]

Dixon, Ruth, Christiane Arndt, Manuel Mullers, Jarmo Vakkuri, Kristiina Engblom-Pelkkala, and Christopher Hood. 2013. A lever for improvement or a magnet for blame? Press and political responses to international educational rankings in four EU countries. Public Admin 91: 484-505. [CrossRef]

Entman, Robert M. 1993. Framing: Toward clarification of a fractured paradigm. Journal of Communication 43: 51-58. [CrossRef]

Entman, Robert M. 2007. Framing bias: Media in the distribution of power. Journal of Communication 57: 163-73. [CrossRef]

Fetherston, Tony, and Geoff Lummis. 2012. Why Western Australian secondary teachers resign. Australian Journal of Teacher Education 37: 1-20. [CrossRef]

Fink, Katherine. 2019. The biggest challenge facing journalism: A lack of trust. Journalism 20: 40-43. [CrossRef]

Goffman, Erving. 1974. Frame Analysis. New York: Free Press.

Goldstein, Dana. 2015. The Teacher Wars: A History of America's Most Embattled Profession. New York: Anchor Books.

Hattam, Robert, Brenton Prosser, and Kathy Brady. 2009. Revolution or backlash? The mediatisation of education policy in Australia. Critical Studies in Education 50: 159-72. [CrossRef] 
Heffernan, Amanda, Fiona Longmuir, David Bright, and Misol Kim. 2019. Perceptions of Teachers and Teaching in Australia; Melbourne: Monash University. Available online: https://www.monash.edu/thank-your-teacher/docs/Perceptions-of-Teachers-andTeaching-in-Australia-report-Nov-2019.pdf (accessed on 15 June 2020).

Heffernan, Madeleine. 2021. 'A Fair Bit of Excitement': Schools on Track for Return to Pre-COVID Routine. The Age. January 20. Available online: https:/ / www.theage.com.au/politics/victoria/a-fair-bit-of-excitement-schools-on-track-for-return-to-precovid-routine-20210120-p56vm2.html (accessed on 1 February 2021).

Johnston, W. M., and G. C. Davey. 1997. The psychological impact of negative TV news bulletins: The catastrophizing of personal worries. British Journal of Psychology 88: 85-91. [CrossRef]

Lingard, Bob, and Shaun Rawolle. 2004. Mediatizing educational policy: The journalistic field, science policy, and cross-field effects. Journal of Education Policy 19: 361-80. [CrossRef]

Liu, Shih-Hsiung, and Shih-Chieh Tsao. 2013. How did the meanings constructed by Taiwanese pre-service teachers from educational news media affect their beliefs? Educational Media International 50: 135-47. [CrossRef]

Mackenzie, Noella. 2007. Teacher morale: More complex than we think? The Australian Educational Researcher 34: 89-104. [CrossRef]

MacMillan, Katie. 2002. Narratives of social disruption: Education news in the British tabloid press. Discourse: Studies in the Cultural Politics of Education 23: 27-38. [CrossRef]

Marin, Marie-France, Julie-Katia Morin-Major, Tania E. Schramek, Annick Beaupré, Andrea Perna, Robert-Paul Juster, and Sonia J. Lupien. 2012. There is no news like bad news: Women are more remembering and stress reactive after reading real negative news than men. PLoS ONE 7: e47189. [CrossRef]

McIntyre, Karen Elizabeth, and Kyser Lough. 2019. Toward a clearer conceptualization and operationalization of solutions journalism. Journalism. [CrossRef]

McIntyre, Karen, and Cathrine Gyldensted. 2018. Positive psychology as a theoretical foundation for constructive journalism. Journalism Practice 12: 662-78. [CrossRef]

McIntyre, Karen, and Rhonda Gibson. 2016. Positive news makes readers feel good: A “silver-lining" approach to negative news can attract audiences. Southern Communication Journal 81: 304-15. [CrossRef]

McNaughton-Cassill, Mary E. 2001. The news media and psychological distress. Anxiety, Stress, E Coping 14: 193-211. [CrossRef]

Mills, Martin, and Amanda Keddie. 2010. Cultural reductionism and the media: Polarising discourses around schools, violence and masculinity in an age of terror. Oxford Review of Education 36: 427-44. [CrossRef]

Mockler, Nicole. 2013. Reporting the 'education revolution': MySchool.edu.au in the print media. Discourse: Studies in the Cultural Politics of Education 34: 1-16. [CrossRef]

Mockler, Nicole. 2015. NAPLAN and the problem frame: Exploring representations of NAPLAN in the print media, 2010 and 2013. In National Testing in Schools. London: Routledge, pp. 181-98.

Mockler, Nicole. 2018. Discourses of teacher quality in the Australian print media 2014-2017: A corpus-assisted analysis. Discourse: Studies in the Cultural Politics of Education 41: 854-70. [CrossRef]

Moore, Tony. 2019. One in Three Australian Teachers Leaves in 5 Years. Brisbane Times, February 25. Available online: https:/ / www.brisbanetimes.com.au/national/queensland/one-in-three-australian-teachers-leaves-in-first-five-yearsinquiry-hears-20190225-p5106h.html (accessed on 31 January 2020).

Newman, Nic, Richard Fletcher, Anne Kalogeropoulos, and Rasmus Kleis Nielsen. 2019. Reuters Institute Digital News Report. Available online: http:/ / www.digitalnewsreport.org/ (accessed on 28 January 2020).

O'Neil, Moira. 2012. Overarching Patterns in Media Coverage of Education Issues: A Core Story of Education Report. Washington, DC: FrameWorks Institute.

Rogers, S. L., L. Barblett, and K. Robinson. 2016. Investigating the impact of NAPLAN on student, parent and teacher emotional distress in independent schools. The Australian Educational Researcher 43: 327-43. [CrossRef]

Rogers, S. L., L. Barblett, and K. Robinson. 2018. Parent and teacher perceptions of NAPLAN in a sample of Independent schools in Western Australia. The Australian Educational Researcher 45: 493-513. [CrossRef]

Rose, Judy, Samantha Low-Choy, Parlo Singh, and Daniela Vasco. 2018. NAPLAN discourses: A systematic review after the first decade. Discourse: Studies in the Cultural Politics of Education 41: 871-86. [CrossRef]

Shine, Kathryn. 2015. Are Australian teachers making the grade? A study of news coverage of NAPLAN testing. Media International Australia 154: 25-33. [CrossRef]

Shine, Kathryn. 2017. 'Everything is negative': Schoolteachers' perceptions of news coverage of education. Journalism 21: 1694-709. [CrossRef]

Shine, Kathryn. 2019. Education coverage. In The International Encyclopedia of Journalism Studies. Edited by Tim P. Vos and Folker Hanusch. Hoboken: John Wiley \& Sons.

Simon, Brian. 1991. Education and the Social Order 1940-1990. London: Lawrence \& Wishart.

Snyder, Ilana. 2008. The Literacy Wars. Crows Nest: Allen \& Unwin.

Stack, Michelle. 2006. Testing, testing, read all about it: Canadian press coverage of the PISA results. Canadian Journal of Education/Revue canadienne de l'Ã@ducation 29: 49-69. [CrossRef]

Szabo, Attila, and Katie L. Hopkinson. 2007. Negative psychological effects of watching the news in the television: Relaxation or another intervention may be needed to buffer them! International Journal of Behavioral Medicine 14: 57-62. [CrossRef] 
Tamir, Eran, and Roei Davidson. 2011. Staying above the fray: Framing and conflict in the coverage of education policy debates. American Journal of Education 117: 233-65. [CrossRef]

Tankard, James W. 2001. The empirical approach to the study of media framing. In Framing Public Life: Perspectives on Media and Our Understanding of the Social World. Edited by Stephen D. Reese, Oscar H. Gandy and August E. Grant. Mahwah: Lawrence Erlbaum, pp. 95-106.

Thier, Kathryn. 2016. Opportunities and challenges for initial implementation of solutions journalism coursework. Journalism $\mathcal{E}$ Mass Communication Educator 71: 329-43.

Thomas, Sue. 2006. Education Policy in the Media: Public Discourses on Education. Teneriffe: Post Pressed.

Thompson, Greg, and Ian Cook. 2014. Manipulating the data: Teaching and NAPLAN in the control society. Discourse: Studies in the Cultural Politics of Education 35: 129-42. [CrossRef]

Thompson, Greg, and Tomaz Lasic. 2011. Doing Something about It: Representations of NAPLAN in the Public Domain. Paper presented at the AARE Annual Conference, Hobart, Australia, 27 November-1 December. Available online: https: // researchrepository.murdoch.edu.au/id/eprint/9816/ (accessed on 13 August 2020).

Thomson, Pat. 2004. Introduction. Journal of Education Policy 19: 251-52.

Ulmer, Jasmine B. 2016. Re-framing teacher evaluation discourse in the media: An analysis and narrative-based proposal. Discourse: Studies in the Cultural Politics of Education 37: 43-55. [CrossRef]

Wallace, Mike. 1993. Discourse of derision: The role of the mass media within the education policy process. Journal of Education Policy 8: 321-37. [CrossRef]

Wallace, Mike. 2007. Educational myth-making with "due accuracy and impartiality"? A current affairs TV episode in the United Kingdom. Peabody Journal of Education 82: 10-31. [CrossRef]

Weaver, David H. 2007. Thoughts on agenda setting, framing, and priming. Journal of Communication 5: 142-47. [CrossRef]

Williams, Philip, and Phil Hemingway. 2020. Donald Trump Insists Schools Reopen But Some Parents, Teachers and Children Fear Coronavirus. Australian Broadcasting Corporation (ABC). September 3. Available online: https://www.abc.net.au/news/2020-0903/trump-insists-schools-open-but-some-parents-fear-coronavirus/12598944 (accessed on 1 February 2021). 